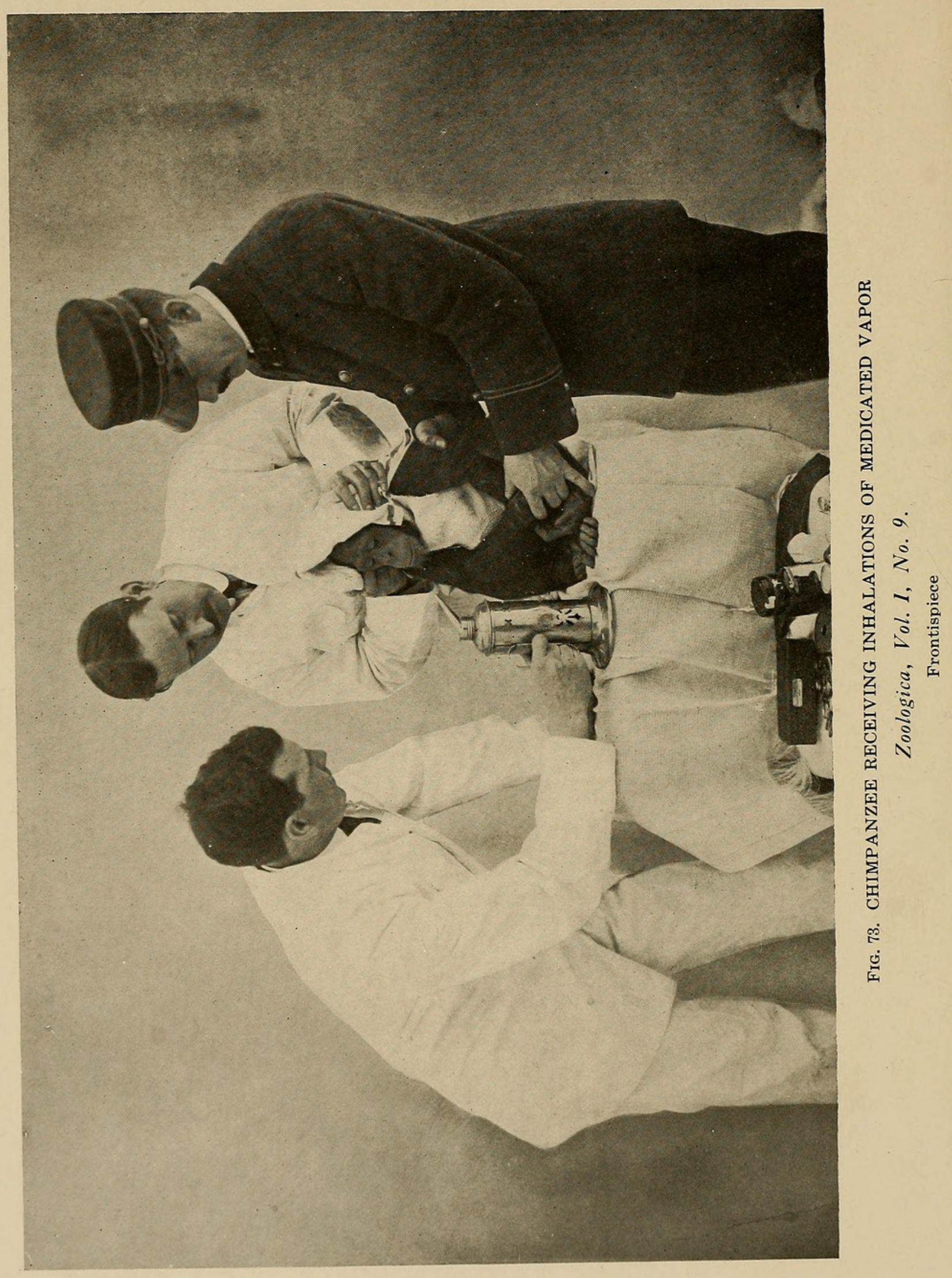




\title{
SOME COMMON AFFECTIONS OF THE RESPIRATORY AND DIGESTIVE ORGANS AMONG PRIMATES
}

\author{
BY W. REID BLAIR, D.V.S.
}

\section{INTRODUCTION.}

In the examination of sick animals it is important to have a definite method or system. A plan of examination should be followed, so that when that task is finished there shall be no important point overlooked; then the examiner is in a position to form an accurate opinion.

A thorough knowledge of conditions that obtain in the healthy animal is of the highest importance, because it is only by a knowledge of what is normal that one can detect the abnormal. A careful study of different species of animals throughout their growth and development, by the individual with good powers of observation and a reflective turn of mind, is of great value. A thorough knowledge of anatomy, the structure of the body, and of physiology or the functions and activities of the body, also lie at the foundation of an accurate diagnosis.

Of course an experienced eye can detect slight alterations or variations from the normal that are not perceptible to the unskilled observer. He who is most familiar with the appearance and deportment of a wild animal in health, at the various periods of its existence, will be in a position to most readily appreciate all departures from the normal. It is also important to know that all animals of different races and families deport themselves differently under the influence of the same disease or pathological process. For instance, a degree of fever that does not produce marked dullness in a nervous, highly strung chimpanzee, may cause the most abject depression in a coarse, plethoric orang-utan. The same is true of many other 
species of wild animals. This, and similar facts are of the greatest importance in the diagnosis of disease and in the recognition of its significance.

\section{HISTORY.}

Before making an examination of a patient, the history of the case is obtained from the keeper. This is very important. Upon this feature alone a fairly safe diagnosis may often be made by the experienced observer. It is important to know something of the origin and development of the disease. The cause of a disease is important, not only in forming a diagnosis, but also in connection with treatment; therefore it should be carefully sought. The character of the food and water, the temperature of the building and the care that the animal has received should all be inquired into closely.

The examination of the sick animal may be general and special. The former refers to symptoms which involve the whole organism, the latter considers the single organs of the body, the secretions and excretions.

In making a general examination the following points should be observed:

1. The physical condition of the patient.

2. The constitutional and nutritive condition.

3. The mucous membranes and the skin.

4. The respiration, temperature and pulse, when the two latter may be obtained without causing undue excitement.

4. The position of the animal when lying down is to a certain extent a diagnostic symptom; very sick animals will not rise when approached. Animals that are affected by lateral or one-sided diseases of the chest-lateral pneumonia or pleurisy-most frequently lie on the affected side; while those cases where there is difficult or labored respiration, as in double pneumonia or fluid in the chest, remain standing with the forelegs well spread, or they assume a sitting position.

The constitutional condition may depend, to a large extent, on the age of the animal, length of time in captivity, how it has been fed, and the amount of exercise it takes; but as a general rule if the animal is in poor condition, it is usually due to the presence of some disease. The skin, to a certain extent, is a good diagnostic guide; if the animal enjoys good health the skin will be loose and easily 
pulled from different parts of the body. In very slight cases of emaciation one must depend, to a certain extent, on the history of the case as obtained from the keeper. A rapid emaciation occurs in diseases of the digestive tract; in all acute or chronic feverish affections, and in certain cases of poisoning.

The visible mucous membranes are examined as to their color. Abnormal paleness may be due to anæmia or internal hemorrhages, or defective heart action. A blue (cyanotic) coloring is sometimes observed where there is defective oxygenation of the blood; pressure on the larynx or trachea; in pneumonia, and in certain heart affections, especially fatty degeneration of the cardiac muscle.

A yellow color (icteric) generally denotes some disorder of the liver, and occurs in certa $n$ infectious diseases. The changes in color of the skin are most readily detected where the hair is thin, as on the belly and the inner surfaces of the thighs. A very red skin indicates a high temperature or the commencement of some skin eruption; if yellow, some disturbance of the liver or portal system is to be suspected.

The hair is also a useful guide in diagnosis. In sick, poorly fed or neglected animals, or those infested with parasites, it loses its gloss, becomes dry and brittle, and in some cases falls out partially or entirely.

Oedema or dropsy of the skin is an abnormal accumulation of fluids in the skin and the subcutaneous cellular tissues. If the swelling be pressed by the finger, the indentation remains visible for some time; this may come from a number of diseased conditions. The swellings are chiefly confined to the lower portions of the body, as the extremities, abdomen and under the chest. It occurs as a complication in diseases of the heart, especially where there is imperfect valvular action, and in acute kidney disorders, and prolonged acute affections.

The temperature of the body is determined by what is technically known as the blood or clinical thermometer. The thermometer is introduced into the rectum and allowed to remain from two to four minutes, according to the sensitiveness of the instrument. In most animals the temperature is highest at five o'clock in the afternoon, and lowest at about the same hour in the morning. An increased temperature of the body above the normal, not due to overheating or to great exertion, is defined as fever. 
A fever, as a rule, begins with a chill or a number of them. There is a shivering or quivering of the muscles and skin and finally of the entire body. If the temperature is high, the animal becomes weak and falls away in weight very rapidly. Increase or decrease of local temperature is generally due to some injury, or a surgical disease.

\section{RESPIRATORY SYSTEM.}

Nasal CatarRh.

This affection, generally spoken of as cold in the head, is indicated by a watery or thick, mucoid discharge from the nose and eyes, and is due to a febrile or inflammatory condition of the mucous membranes of the nasal chambers or the frontal sinuses, which may arise from damp, cold or contagion.

Symptoms:-Frequent sneezing, nasal and lachrymal discharge, cough, dullness and inclination for warmth.

Treatment:-Acute catarrh is usually transient and does not often require local treatment. Steaming the head with eucamphol will afford soothing relief if the head is very stuffy from becoming clogged with the collected discharge. Vaseline rubbed into the nasal openings prevents the hard, dry, irritating crusts forming as the result of the discharge from the nostrils.

If the animal can be taught to use a blanket to sleep in, these annoying nasal colds will generally be avoided. Careful regard as to warmth and comfort will generally suffice to prevent them.

\section{Laryngitis. Pharyngitis. Sore Throat.}

Animals affected:- Primates generally.

Causes:- Chiefly faulty hygiene; infection of influenza.

Symptoms:-There is usually more or less difficulty in swallowing, swelling around the throat and under the ears, husky cough and tenderness on pressure. The inspiratory act is accompanied by a rasping or deep bass sound, particularly after the slightest exertion. There is sometimes the general symptom of fever more or less marked, with hastened breathing and red-injected eyes and nostrils.

While sore throat is rarely fatal in primates, its effects are not unimportant or trivial. It occasionally merges into a chronic form, 
with a troublesome, hacking cough, tenderness to pressure and an increased liability to diseases of the air passages.

Treatment:-A roomy, clean, dry cage should be allowed, care being taken to avoid draughts of cold air, and to secure a soft equable temperature of about $70^{\circ}$. The throat should be well, but gently, rubbed with camphorated oil. Inhalation of eucamphol or compound tincture of benzoin in hot water, should be given every two hours. If the cough is troublesome, a few grains of Dover's powder should be given two or three times a day. The diet should be confined to warm, nourishing gruels or milk and brandy, sweetened lemon juice or coffee. In cases attended with high fever and bright red nasal membrane, laxatives and diuretics are especially needed. Ten drops of the fluid extract of cascara sagrada should be given at the outset, and five grains of acetate of potassium given twice daily, allowing the animal to drink all the warm water possible.

\section{BRONCHITIS.}

This disease is an inflammation of the mucous membrane of the bronchial tubes. When the smaller bronchial tubes are involved, the affection is termed capillary bronchitis, and this form is most common in very young, very old or debilitated animals. The disease is exceedingly common among all primates, and especially so in the chimpanzee.

Causes:-Bronchitis may arise from irritating dust inhalation, exposure to damp and cold and sudden changes of the temperature of a building.

Symptoms:-Quick wheezing respiration, frequent and prolonged coughing. The cough at first dry, later becoming moist and thick. The eyes become red and inflamed and there is usually considerable sneezing with nasal discharge. The heart beats are greatly increased, and on placing the ear to the animal's chest, a moist rattle is heard. The animal becomes prostrate, and unless speedily relieved, quickly succumbs to broncho-pneumonia or asphyxia.

Treatment:- The patient should be placed in comfortable atmosphere, free from draughts or dampness. Mild cases are relieved by inhalation of a sedative steam arising from a pail or steam evolved from an ordinary human bronchitis kettle. When treating animals which are easily controlled, or confined, little difficulty will be ex- 
perienced in carrying out this treatment, as the patient quickly appreciates the relief afforded. Extremely bad cases in chimpanzees and orangs have been treated successfully in this way. Ferocious animals may be confined in a small cage or shifting box which can be covered with a blanket or canvas for the purpose of confining the steam.

The steaming should be continued for only a few minutes at a time, but repeated several times a day.

The food should be nutritious and concentrated; bulky food should be avoided. The sweetened juice of oranges and lemons is very beneficial and should be given quite freely.

The throat and chest should be well rubbed with camphorated oil, when possible. In all forms of bronchitis, counter-irritation and the chest-jacket are very useful.

Inhalations of compound tincture of benzoin, or eucamphol mixed with water, in the proportion of one tablespoonful to a cup of water, will be found most useful. Eucamphol is a compound composed of carbolic acid, oil of camphor and eucalyptus oil. It has a very pleasant odor, which is acceptable to the animals and it is very soothing to the bronchial mucous membranes.

When the cough is very troublesome and harsh, give a mixture of carbonate of ammonium with Brown mixture, as follows:

R

Ammonium Carbonatis.......................

Misturæ Glycyrrhizæ Comp. (Brown Mix.)......... כ̌iv

$M$.

Sig:- Give a half-grown chimpanzee $1 / 2$ teaspoonful every 4 or 5 hours, in milk or the juice of orange.

\section{PNEUMONIA.}

Pneumonia is an inflammation of the substance of the lungs, and may be confined to a portion of one lobe or may include the greater part of both lungs. It is a disease that carries off a considerable portion of all wild animals in confinement, both as a primary affection, and as a complication of other diseases, especially those of a debilitating character.

Among primates, the most common type met with is bronchopneumonia, in which only limited and usually scattered portions of the lungs are involved. 


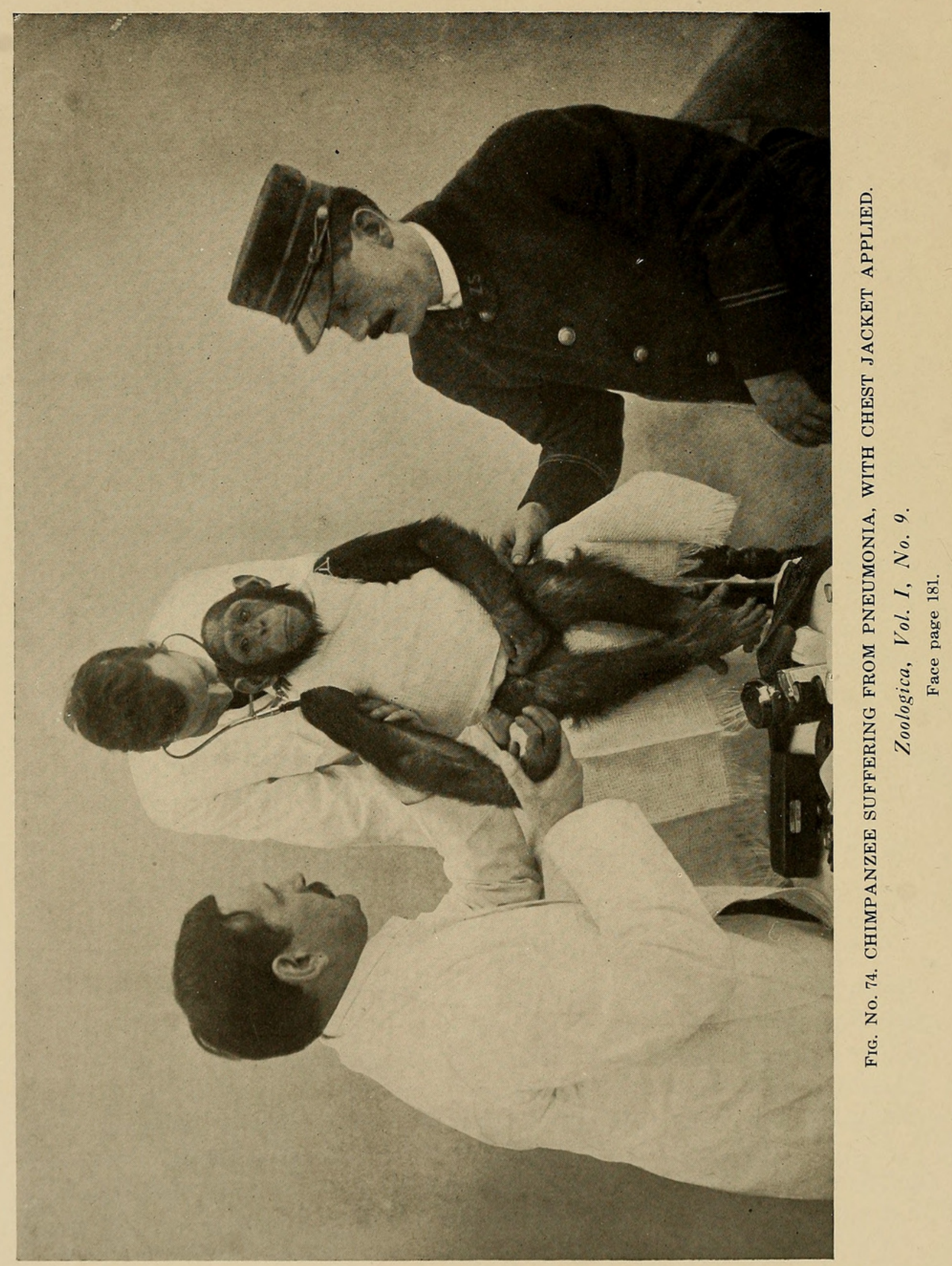


Causes:- The onset is favored by exposure to cold or anything inducing a chill. Microscopic examination of the discharges coughed up shows, in many cases, an abundance of various bacteria of infectious nature. These examinations have convinced me that in the treatment of this disease, it is safe to regard all cases as infective. This type of pneumonia is most common as a complication of bronchitis.

Tuberculous broncho-pneumonia of primates will be spoken of under tuberculosis.

Symptoms:-The usual preliminaries are frequent shiverings and general febrile disturbances shown by increased temperature and high pulse. The breathing is seen to be short and gasping, and an irritable cough is present. The eyes are red, and the nose hot and dry. On placing the ear to the animal's side, increased lung sounds are heard, which ultimately become obliterated as the disease proceeds, as a result of the filling up of the air spaces with congested blood. If only one lung is involved, the animal will lie on the affected side, thus allowing the sound lung to be relieved of all possible pressure. In pneumonia too great reliance cannot be placed on physical signs alone, as there may be very grave disease without the former being at all well pronounced. Prostration with very slow or very rapid heart action are indications calling for the most watchful treatment, especially if with these there is much difficult breathing, and blueness of the mucous membranes, indicating that the blood is being very poorly ventilated.

Treatment:- This consists of active counter-irritation to the sides of the chest, diffusible stimulants, bodily warmth, free ventilation, and nourishing food. In all forms of lung affection counterirritation combined with a "chest-jacket" will be found of great value.

The object of a chest-jacket is to have a close-fitting coat or bandage, which shall absorb the moisture from the animal's skin and protect it from variations in the external temperature. The exact construction is of minor importance, provided it is of even thickness, fits closely, and can be kept in place. In winter it may be made of two layers of flannel, with or without padding of cotton-wool quilted in. Openings may be made for the forelegs. Closeness of fitting without being so tight as to embarrass the breathing is important, both to preserve it in position, and to prevent the access of cool air. 
Often the animal will breathe easier at once when the dressing is applied. The food should be light at first, unless there be marked prostration, and largely fluid while the fever is high. Alcohol baths are useful in reducing excessive temperature.

If there is evidence of pain a few grains of Dover's powder, on account of its favoring the action of the skin and kidneys, will be found beneficial. If the disease is of a low type from the first, with evidences of great weakness or positive prostration, the chief reliance must be on good feeding and alcohol, with such stimulants as carbonate or muriate of ammonium, strychnine or caffein. Whiskey or brandy, given in doses of a teaspoonful or less with beef juice or eggnog, if the animal refuses nourishment, or diluted with water, given simply as a medicine, often produces the happiest effects. If the animal will not take nourishment it must be forced upon it, if possible, with as little exhaustion of its strength as necessary.

If the heart becomes very weak or irregular, resort must be had to digitalis, say three to five drops for a half-grown orang or chimpanzee. It is a most valuable remedy in careful hands. Death in pneumonia is nearly always by heart-failure, and this organ must therefore be carefully observed throughout. During convalescence, if the appetite is not good, vegetable bitters - as nux vomica and gentian will be useful. Quinine is a well-tested and safe remedy for monkeys generally, and small tonic doses - one to two grains - may be given three times daily.

\section{GISEASES OF THE DIGESTIVE SYSTEM.}

\section{INDIGESTION.}

Vomiting, Gastritis, Stomach and Intestinal Parasites, Gastroenteritis. Prolapsed Rectum.

The term indigestion implies imperfect discharge of the functions of the digestive tract. The symptoms may manifest themselves without actual structural or organic disease of the digestive organs, being visible to the naked eye. The cause is generally improper diet. Indigestion also arises from diseased teeth and imperfect mastication. Cold, heavy and soggy rice, due to improper steaming will cause acute colic pains.

Few monkeys are proof against the temptation to overeating. 
Some are natural gluttons and on gaining access to food, will rapidly overload the stomach. The food is literal'y bolted whole, with no admixture of saliva, and no facility for admixture of the gastric juices, even if the overloading had left the stomach capable of secreting the latter.

Symptoms of Indigestion:-Uneasiness, pain, abdominal distension, labored breathing due to the distended stomach pressing hard against the diaphragm.

Treatment:- The diet is usually the first matter to be considered, and if it is rich and stimulating, should be replaced by easily digested materials.

In many of these cases we have found that special dieting or positive abstinence from food for a time, proves most serviceable. A little warm milk with one-fourth of lime-water has a marked corrective effect in these cases. If there is much distension of the abdomen, aromatic spirits of ammonia with subnitrate of bismuth should be given. Gentle hand-rubbing of the abdomen with warm cocoanut oil, and warm-water; rectal injections are useful, if constipation is also present.

\section{GASTRITIS, ENTERITIS AND DYSENTERY.}

Among primates the most important diseases of the digestive system are gastritis, or inflammation of the stomach; enteritis, or inflammation of the small intestine; dysentery, or inflammation of the large intestine.

Instead of giving systematic description of each of these affections, we propose to direct our remarks as to how to discriminate between them, and with special reference to treatment.

The common causes are generally unsuitable food; either too coarse and bulky, too stimulating, or too hot or too cold. Food that has soured by lying over night in the cage and then eaten by the animal is very prone to set up gastric disturbances.

Symptoms:- The symptoms of these affections are much the same, and may also be conveniently grouped. One of the marked symptoms of these disorders in the domestic animals is vomiting. Among primates vomiting, except on rare occasions, seldom occurs. It is most difficult for a monkey to relieve its stomach by vomiting. When vomiting is observed in these animals, the presence of some irritating food or poison should be suspected. Large round worms in the 
stomach have been known to induce violent vomiting. If the vomit consists of mucus stained with dirty yellowish bile, tuberculosis of the liver is to be suspected. Foreign bodies, such as pieces of blanket, sticks, or nails which are apt to lodge near the pyloric opening of the stomach, also induce vomiting.

In gastritis and enteritis, pressure on the abdomen shows pronounced tenderness or pain, whereas, with the colicy pains of indigestion, by massaging the abdomen the pain is appreciably lessened. The appetite is somewhat modified, and soon after the animal has partaken of food, it will be uneasy and isolate itself; thirst is pronounced; the bowels moving frequently; the fæces at first are very soft and later the evacuations are composed of fluid and mucus which may be streaked with blood. At this stage the animal becomes very weak, and emaciation is rapid.

When the large intestine becomes involved, the fæces are generally fluid, frequently blood-stained, and usually passed without effort.

Treatment:- In beginning treatment for acute diarrhœa or dysentery, it is always wise to give a dose of castor oil or olive oil, in order to make sure that the bowels are free from irritating substances. A few drops of tincture of opium to relieve the pain should be added to the oil. This treatment alone will frequently be found to effect a cure. If the symptoms with diarrhœa persist, then small doses of paregoric and subnitrate of bismuth should be given every few hours. All solid food should be withheld. The whites of eggs beaten up in milk, with the addition of a teaspoonful of blackberry brandy, should be the principal food for the first few days. A few drops of tincture of opium in a little barley-water is also of value when the stomach is very sensitive.

The return to solid food should be most gradual and approached with the greatest care, as the gastric and intestinal mucous membranes remain in an extremely sensitive condition for a considerable period after these affections. A tablespoonful of lime-water added to each four ounces of warm milk will be found to be of great benefit while the stomach remains sensitive.

\section{PROLAPSE OF THE ANUS.}

This condition denotes an eversion of the lower portion of the rectum, and its protrusion through the anus. The affection may be 
seen in almost any animal, but has been most frequently observed among monkeys suffering from dysentery, or anything which will cause the animal to unduly strain, as in chronic constipation or any laxity or weakness of the external sphincters. Simple prolapsed rectum is easily recognized as such. A typical protrusion presents the appearance of a curved cylinder with the mucous membrane considerably swollen. In the early stages the protruding tissue is covered with mucus and prone to bleed on coming in contact with the rough hay or straw of the bedding.

Treatment of eversion of the rectum in some cases will be most difficult; but in other cases very simple. When the everted rectum has not become congested, it may be returned to its proper position by a little lubricant.

If any difficulty is experienced, the fore-finger should be well oiled, and by a digital kneading process, commenced at the extremity of the protrusion, the latter is gradually worked through the anus into the proper position.

Tannic acid, one part, and vaseline, five parts, should be smeared over the rectal mucous membrane, and all food should be withheld from the animal for at least twenty-four hours, and then milk with twenty to thirty grains of sulphur given twice daily.

\section{INFECTIVE UlCERATIVE Dysentery IN APES.}

During 1901 there occurred an epidemic of dysentery among the orangs, which also affected a chimpanzee, with the result that all of these animals, five in number, died.

From the coincidence of four or five cases occurring at the same time, acute intestinal irritant was suspected, and as the apes had been receiving small quantities of cod-liver oil, it was thought that the irritant matter might have been introduced through this medicine.

The cases proved obstinate and the disease progressed steadily from the beginning, although one or two of the cases yielded temporarily to treatment.

Many of the best known intestinal antiseptics were administered under the direction of Dr. Miller. These included salol, subnitrate and sub-gallate of bismuth, xeroform, opium, etc., but all proved equally ineffectual. Irrigation of the colon by enemas of sterilized 
normal salt solution, and quinine bisulphate were administered without appreciable result.

The disease progressed steadily, the animals dying within a few days of each other. The post-mortem examinations were made by Dr. Brooks, who was able to identify the cause of the disease to be the invasion of the intestinal mucosæ by the Balantidium coli (Paramœcium coli), a parasite belonging to the Order Heterotricha. This organism was discovered by Molmsden in 1857, in the mucus discharges of a patient who suffered from a persistent diarrhœa following cholera. The Balantidium is an oval body, about six or seven times the diameter of a human red-blood cell; is quite actively motile, but soon ceases its movements if exposed to cold, acids, or disinfectants.

The lesions produced by the Balantidium coli are principally confined to the large intestine, where in the case of the orangs, the entire mucous membrane of the colon was transformed into an almost continuous succession of large irregular ulcers. Microscopic examination of sections of these ulcers showed myriads of parasites burrowing beneath the mucous membrane, even along the lymphatic channels of the muscular coat and in places as far down as the peritoneum.

Just how this deadly protozoan first reached the apes remained for several months a complete mystery. A diligent microscopic search of the fæces of all possible sources of immigrat on was finally rewarded by the startling discovery that the fæces of the giant tortoises from the Galapagos Islands, exhibited during the summer in a yard surrounding the open-air cages of the orang-utans, were swarming with Balantidii but which had not caused these reptiles the least inconvenience.

Owing to the danger of this parasite to the higher apes, and the unsatisfactory treatment, it is important that an early diagnosis should be made in suspected cases of dysentery in apes, in order that strict isolation of infected ones should be carried out. An easy and positive examination may be made by microscopic examination of the fæcal discharges of infected animals when the actively motile Balantidii are to be seen. 


\section{$2 \mathrm{BHL}$ Biodiversity Heritage Library}

Blair, W. Reid. 1912. "Some common affections of the respiratory and digestive organs among primates." Zoologica: scientific contributions of the New York Zoological Society 1(9), 174-186. https://doi.org/10.5962/p.319113.

View This Item Online: https://www.biodiversitylibrary.org/item/97326

DOI: https://doi.org/10.5962/p.319113

Permalink: https://www.biodiversitylibrary.org/partpdf/319113

\section{Holding Institution}

Harvard University, Museum of Comparative Zoology, Ernst Mayr Library

\section{Sponsored by}

Harvard University, Museum of Comparative Zoology, Ernst Mayr Library

\section{Copyright \& Reuse}

Copyright Status: Public domain. The BHL considers that this work is no longer under copyright protection.

This document was created from content at the Biodiversity Heritage Library, the world's largest open access digital library for biodiversity literature and archives. Visit BHL at https://www.biodiversitylibrary.org. 